\title{
Recycling of WEEE Plastics Waste in Mortar: The Effects on Mechanical Properties
}

\author{
Alessandra Merlo ${ }^{1}$, Luca Lavagna ${ }^{1,2, *(\mathbb{D})}$, Daniel Suarez-Riera ${ }^{3} \mathbb{D}$ and Matteo Pavese ${ }^{1,2}$ (D) \\ 1 Department of Applied Science and Technology DISAT, Politecnico di Torino, C.so Duca Degli Abruzzi 24, \\ 10129 Torino, Italy; alessandra.merlo@polito.it (A.M.); matteo.pavese@polito.it (M.P.) \\ 2 National Interuniversity Consortium of Materials Science and Technology (INSTM), Via G. Giusti 9, \\ 50121 Florence, Italy \\ 3 Department of Structural, Geotechnical and Building Engineering, Politecnico di Torino, C.so Duca Degli \\ Abruzzi 24, 10129 Torino, Italy; daniel.suarez@polito.it \\ * Correspondence: luca.lavagna@polito.it; Tel.: +39-01-1090-4598
}

Citation: Merlo, A.; Lavagna, L.; Suarez-Riera, D.; Pavese, M. Recycling of WEEE Plastics Waste in Mortar: The Effects on Mechanical Properties. Recycling 2021, 6, 70. https://doi.org/10.3390/ recycling 6040070

Academic Editors: Michele John and Wan-Ting (Grace) Chen

Received: 21 September 2021

Accepted: 20 October 2021

Published: 22 October 2021

Publisher's Note: MDPI stays neutral with regard to jurisdictional claims in published maps and institutional affiliations.

Copyright: (c) 2021 by the authors. Licensee MDPI, Basel, Switzerland. This article is an open access article distributed under the terms and conditions of the Creative Commons Attribution (CC BY) license (https:// creativecommons.org/licenses/by/ $4.0 /)$.

\begin{abstract}
This work focused on the recycling of WEEE plastic waste as a partial substitute for aggregate in light mortars. The plastic mix, provided by the IREN group, was used as a replacement of aggregate in $15,30,45,60,75$, and $90 \%_{\mathrm{vol}}$ in mortars. Worsening of the mechanical performance of around $50 \%$ was detected already at only $15 \%$ vol of mineral aggregate substituted with plastic waste. The explanation of this phenomenon was found in both the scarce mechanical properties of the used plastic and in the poor adhesion between matrix and plastics that resulted in extra-porosity formation, as also demonstrated by comparing the results with several models in the literature. However, the use of plastic waste as a partial replacement of natural aggregate contributes to the preservation of natural resources and, in any case, does not limit the application of these materials in non-structural applications.
\end{abstract}

Keywords: mortar; recycle; mechanical properties; WEEE recycling; waste plastic

\section{Introduction}

In 2018, global plastics production reached nearly 360 million tons, of which almost 62 million tons corresponded to the production of plastic in Europe alone [1]. These materials are used in large quantities for toys, shopping and garbage bags, packing films, fluid containers, household industrial products, wrapping materials, electronic devices, and building materials, to name a few examples [2]. However, at the end of its life, plastic can be harmful to the environment, raising doubts about the overall benefits of its widespread use. Even though in 2018, the amount of plastic waste sent for recycling doubled compared to 2006 (from 4.7 Mt to 9.4 Mt) and re-use and recovery are well-established practices around the world, the amount of post-consumer plastic waste collected continues to increase: in fact, in 2018, there was an increase of 19\% compared to 2006, specifically, from $24.5 \mathrm{Mt}$ in 2006 to almost $30 \mathrm{Mt}$ in 2018, of which, 25\% (more than $7 \mathrm{Mt}$ ) continued to be sent to landfills [3], since recycling remains a costly and challenging task.

A good way to immobilize plastic waste and avoid landfilling is to re-use these waste materials in the building sector, particularly as substituents of sand or gravel in concrete and mortars. The expected benefits of using waste plastic in concrete are illustrated in the work by $\mathrm{Gu}$ et al. [4], where the economic advantage of using waste in the construction sector is shown. From an environmental point of view, the use of waste materials in the building sector decreases the amount of landfilled plastic materials [5,6].

Generally speaking, in the literature, it is possible to find numerous examples of the substitution of cement or aggregate with waste products [7-12], and plastic waste has been extensively studied in this scope [4,13-23]. While mineral substitutions only slightly affect the mechanical properties of mortar or concrete, in the case of plastics, the experimental 
data all point in the direction of a significant loss in mechanical properties when such substitution occurs. The entity of the reduction in mechanical performance is affected by various parameters such as the component substituted (coarse [19,20], fine [17,18,24,25], or both [21] aggregates, or cement [22]), the substituted quantities $(\%$ vol $[17,18,20,21,23-26]$ or $\%$ weight $[22,24,27,28])$ and the nature and size of both substitute and substituent.

Here, we explain the findings of the most interesting papers in the literature in detail. Kou et al. [17] used rigid polyvinyl chloride (PVC) with a decrement of compressive strength of 9.1, 18.6, 21.8, and $47.3 \%$, respectively, for replacements of 5, 15, 30, and $45 \%$ of sand. In the same line of work, Senhadji et al. [18] showed that compression strength displayed decrements of approximately 3,13,17, and 19\% for replacements of 10, 30, 50 , and $70 \%$ of sand. Instead, Almeshal et al. [24] utilized up to $50 \%$ of polyethylene terephthalate (PET) polymers as a partial replacement for sand in concrete. It was observed that sand substitution damaged the mechanical characteristics of the concrete at different levels. The researchers found a compressive and flexural strength reduction at 28 days from $30 \%$ to $60 \%$ and from $58 \%$ to $84.2 \%$, respectively, when $40 \%$ and $50 \%$ of PET was used. Additionally, Jasim M Abed et al. [28] studied the effect of waste PET on the mechanical properties of mortar; they used five different PET substitution rates, 5, 15, 25, and 50\%. The study showed that PET-containing mortars with $15,25 \%$, and $50 \%$ of PET substitution had a reduced compressive strength, from around $28 \mathrm{MPa}$ (Control) to 27-18-12 $\mathrm{MPa}$, respectively. Additionally, the flexural strength properties decreased by up to $40 \%$. Despite the compressive strength results $(18 \mathrm{MPa})$, the researchers found that the mixture containing $25 \%$ waste PET could be considered a lightweight mortar suitable for structural purposes. Maher Al-Tayeb Mustafa et al. [25] investigated the effect of the partial replacement of sand $(5 \%, 10 \%$, and $20 \%)$ by plastic waste on the mechanical properties of concrete. In this case, the average compressive strength decreased by 7,12 , and $24 \%$ with 5,10 , and $20 \%$ of sand volume replacement. In all these studies, the plastic used was less than $5 \mathrm{~mm}$ in size.

In this work, we present a case of Waste Electrical and Electronic Equipment (WEEE)derived plastics substituting fine aggregate in mortar, and we show in detail how the effects are mainly due to the chemical compatibility between plastic and the matrix, thus providing a solid basis on which future studies may focus to improve mechanical properties.

\section{Results and Discussion}

\section{Mechanical Properties}

Flexural strength (Figure 1A) decreased significantly with an increase in the substitution of sand with plastic waste. However, the trend is not linear: the reduction in flexural strength was around $37 \%$ for only $15 \%_{\text {vol }}$ substitution and reached almost to $50 \%$ at $45 \%$ vol of plastic waste. A more linear behavior of the flexural strength with respect to the plastic waste could be observed between $15 \%$ vol and $90 \%_{\mathrm{vol}}$ of substitution.

A very similar trend was obtained for compressive tests, as shown in Figure 1B. At only $15 \%_{\mathrm{vol}}$ in volume of sand substituted with plastic waste, compressive strength presented a 35\% drop, as in the case of flexural strength. Additionally, in this case, at $45 \%_{\mathrm{vol}}$, the compressive strength was roughly half of the standard mortar, with a further reduction for higher plastic substitution. 

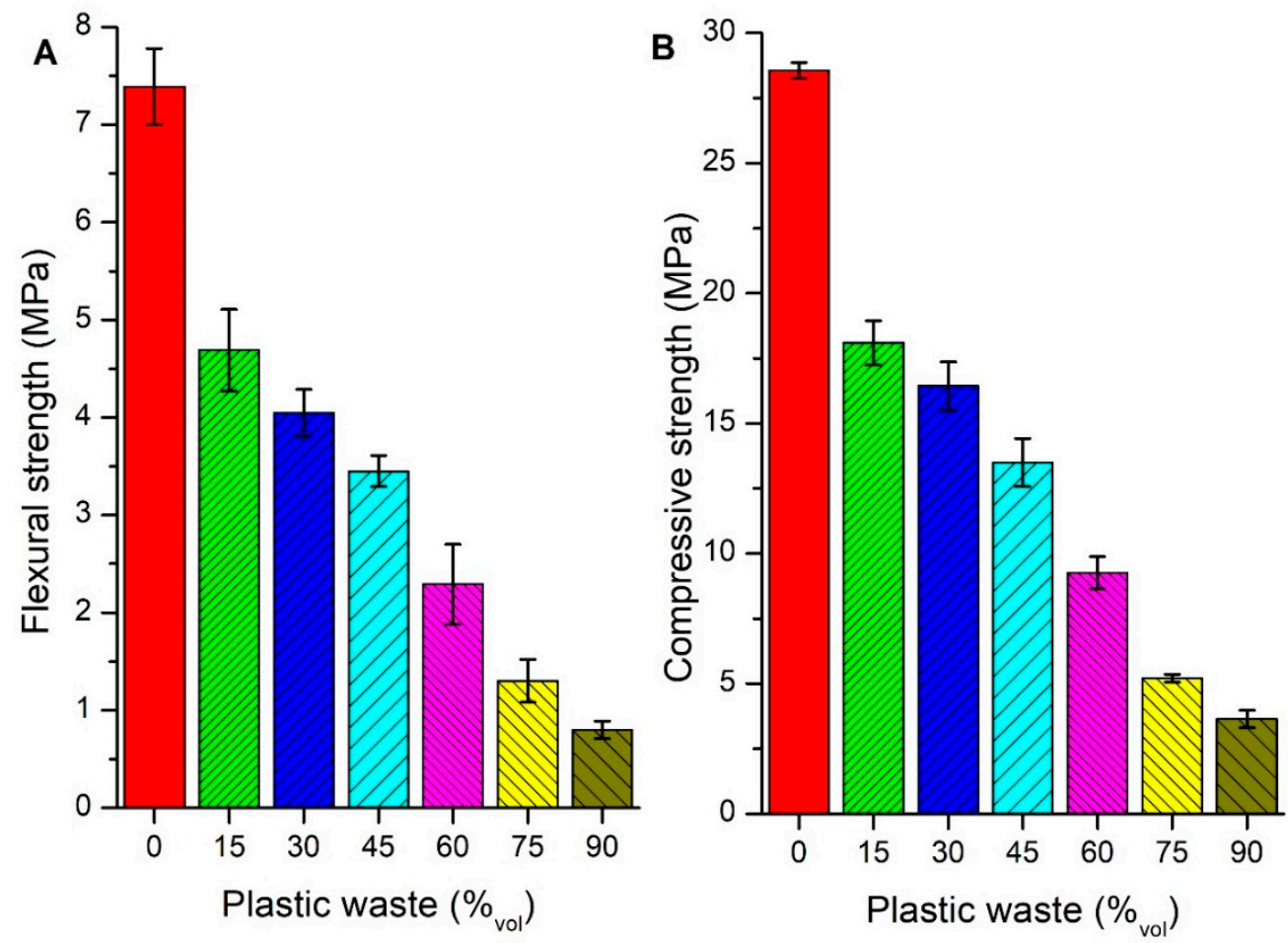

Figure 1. Mechanical properties of plastic-substituted mortar as a function of the percentage of sand substituted with waste plastics: (A) flexural strength, (B) compressive strength.

This worsening in mechanical properties for plastic-substituted mortars can be explained by considering two aspects: firstly, the difference in mechanical and physical properties between the natural aggregate and the plastic substituent [23,29]; secondly, the very different chemical interactions that natural aggregates or plastic substituents have with cement [30]. In fact, the plastic has a much lower Young's modulus than sand (a few GPa versus several tens of GPa) and also much lower strength. Moreover, its thermal expansion coefficient is much higher (roughly one order of magnitude). In addition, the sand used in ordinary mortars is a polar material and chemically interacts well with the cement surface, which is polar too. This allows a good surface adhesion and therefore a good mechanical performance of the material thanks to a stronger interface. The chemical composition of plastic waste differs largely from that of natural aggregates, since plastic is composed of organic compounds that have much lower polarity and therefore cannot generate hydrogen bonds with cement. The low interface adhesion between cement and plastic thus results in a loss in mechanical properties.

The presence of cracks and porosities at the interface between plastic and cement is a clear indication of the poor adhesion between these two components, and can be observed through stereomicroscopy (Figure 2).

In particular, the stereomicroscopy images allow one to confirm the presence of two types of defects. At low particle content, cracks are mainly observed between plastic particles and cement. These cracks are most probably due to the different physical properties of cement and of plastic waste. A possible effect of the polishing procedure on the separation between cement and plastic particles cannot be completely ruled out, notwithstanding the careful polishing procedure; in any case, the presence of cracks demonstrate the poor interfacial strength between the cement matrix and the plastic waste particles. At a higher plastic content, large porosities between the plastic waste particles begin to occur, probably due to the nonoptimal granulometric distribution of the plastic and thus to the poor packing of these aggregate substitutions. This porosity can also form because of the fact that plastic particles tend to aggregate during mixing, probably due to their hydrophobic nature, that is also the responsible for the poor interfacial adhesion with cement. 


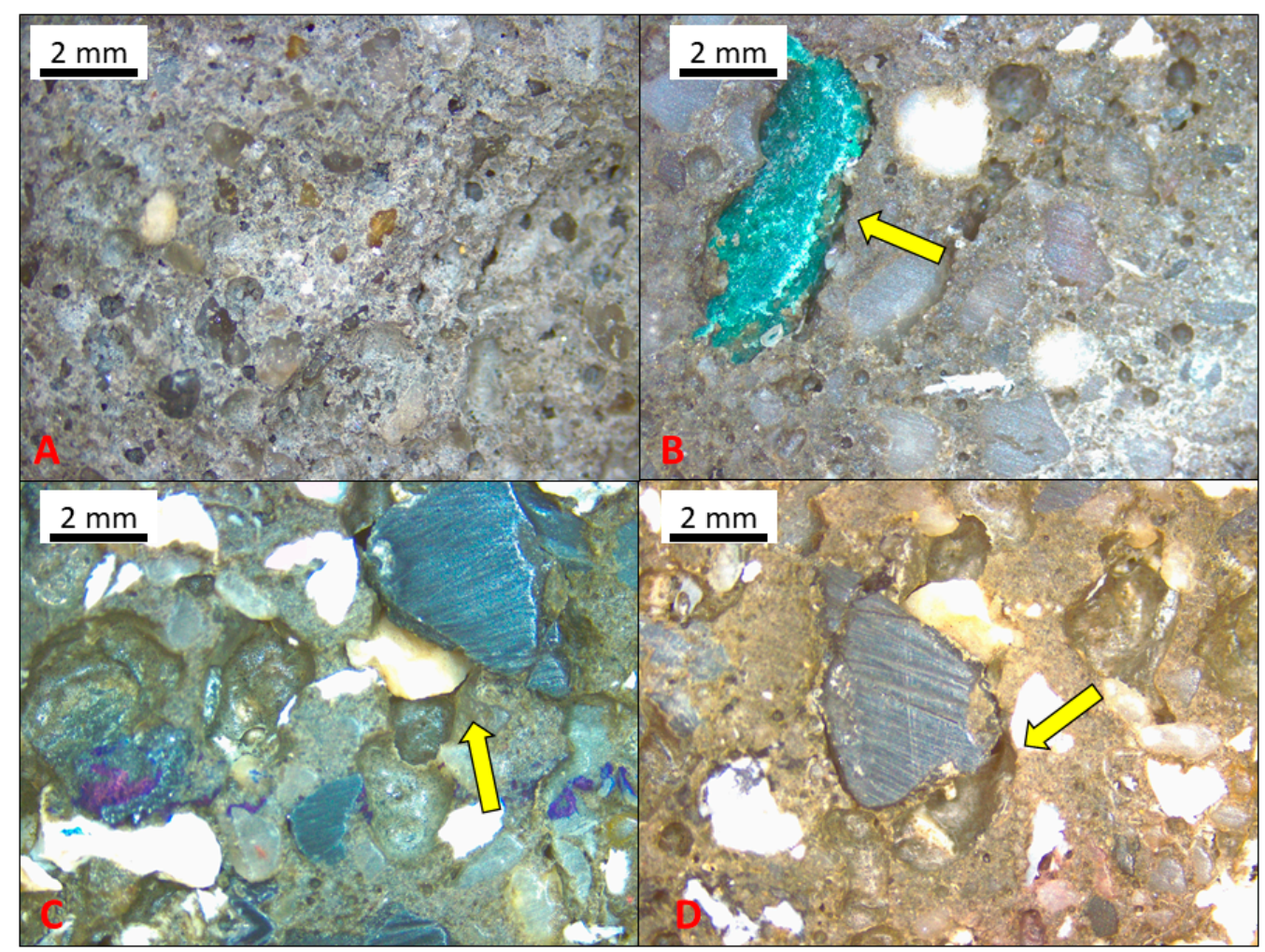

Figure 2. Stereomicrographs of mortars (A) 0 PW, (B) 30 PW (C) 60 PW and (D) 90 PW; yellow arrow indicates the lack of adhesion.

The microscopic analysis confirmed the density measurements provided in Figure 2B: at low plastic substitutions, the pore volume is not much higher than the theoretical value for a mortar at a $\mathrm{w} / \mathrm{c}$ ratio equal to 0.5 . Instead, at high plastic substitutions, the density further decreases due to the formation of additional pores.

The porosity located at the interface between plastic and cement is particularly detrimental to the mechanical properties because it reduces the possible chemical and mechanical interaction of the plastic with the cement. Thus, the plastic aggregates risk not properly interacting with the cement, acting almost as porosities from the mechanical point of view.

To evaluate this effect, additional porosity with respect to the reference sample was calculated from density values and correlated with mechanical properties through different models present in the literature, specifically the Balshin model [31], shown in Equation (1), the Ryshkewitch model [32], shown in Equation (2), the Hasselman model [33], shown in Equation (3), the extended Zheng model [34], shown in Equation (4), and the Schiller model [35], shown in Equation (5).

$$
\begin{gathered}
\sigma=\sigma_{0}(1-p)^{b} \\
\sigma=\sigma_{0} e^{-k b} \\
\sigma=\sigma_{0}-c p \\
\sigma=\sigma_{0}\left[\left(\frac{p_{c}-p}{p_{c}}\right)^{1.85}\left(1-p^{\frac{2}{3}}\right)\right]^{\frac{1}{2}} \\
\sigma=n \ln \left(\frac{p_{0}}{p}\right)
\end{gathered}
$$


In these equations, $\sigma$ is the strength (but the same model can be applied to Young's modulus), $\sigma_{0}$ is the strength at zero porosity, $p$ is the porosity, $p_{0}$ is the porosity at zero strength, $p_{c}$ is the porosity percolation threshold, and $\mathrm{b}, \mathrm{c}, \mathrm{k}$, and $n$ are empirical parameters.

The choice of the porosity values here is not at all trivial, since cement paste possesses an inherent porosity. However, at $\mathrm{w} / \mathrm{c}=0.5$, the cement porosity is very small in size, mainly being the porosity of the gel (submicrometric) or the capillary porosity, residing in the size range of micrometers [36,37]. The porosity linked to the presence of the plastic aggregates is much larger than the gel or capillary porosity of cement, and for this reason, the difference in porosity with respect to the reference sample was chosen.

The same correlation between experimental data and models was carried out considering, in lieu of porosity, the sum of porosity and of plastic substituent. This approach was used since plastic has low adhesion to the cement matrix, as shown in Figure 3, and a remarkably lower modulus than cement or sand. In the extended Zheng model [34], for instance, it is hypothesised that the pores are a second phase with zero elasticity modulus, which is also an acceptable assumption when the second phase modulus is much lower than the matrix one.

In Figure 3, the results of the fitting of the experimental data with the different models are presented. Five models are employed for the fitting, namely Balshin, Ryshkewitch, Hasselman, Zheng, and Schiller, considering these two cases: in the left column (A), the porosity is only the extra-porosity with respect to reference sample (where only cement porosity was present). In the right column (B), the porosity is the extra-porosity plus the plastic aggregate. The $\mathrm{R}^{2}$ of the various fits are shown in the legend of each figure and presented in Table 1.

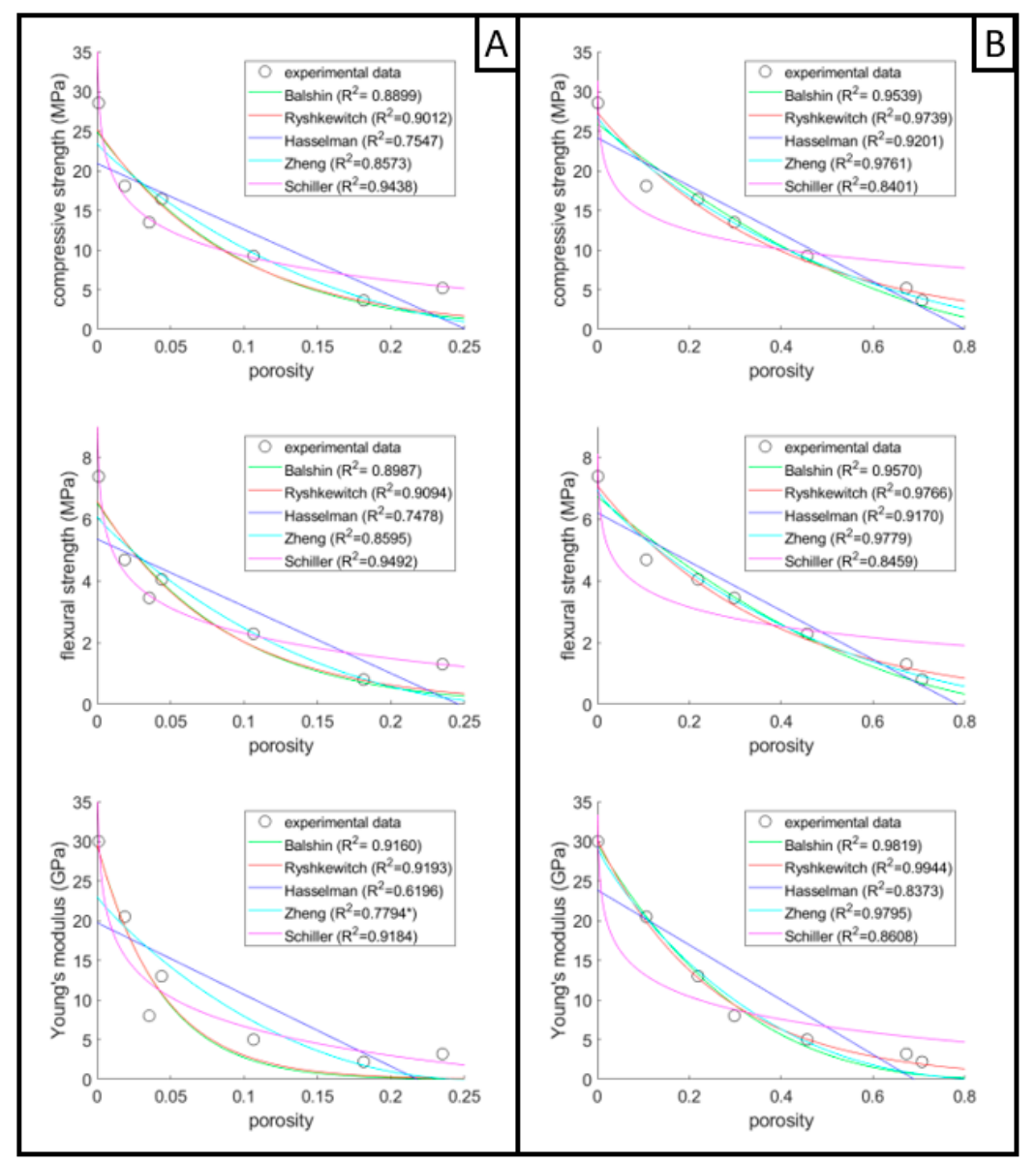

Figure 3. Correlation between compressive strength, flexural strength, Young's modulus and porosity of the pristine mortar and mortar containing $15,30,45,60,75$, and $90 \%_{\mathrm{vol}}$ of waste plastic. (A) the porosity is only the extra-porosity $(\mathbf{B})$ the porosity is the extra-porosity plus the plastic aggregate. 
Table 1. $R^{2}$ values relative to the fitting curves of Figure 3, related to the Balshin, Ryshkewitch, Hasselman, Zheng, and Schiller models.

\begin{tabular}{|c|c|c|c|c|c|c|}
\hline Property & $\begin{array}{l}\text { Type of } \\
\text { Porosity }\end{array}$ & Balshin & Ryshkewitch & Hasselman & Zheng & Schiller \\
\hline \multirow{2}{*}{$\begin{array}{l}\text { Flexural } \\
\text { strength }\end{array}$} & $\begin{array}{c}\text { Only } \\
\text { extra-porosity }\end{array}$ & 0.8987 & 0.9094 & 0.7478 & 0.8595 & 0.9492 \\
\hline & $\begin{array}{l}\text { Extra-porosity }+ \\
\text { plastic }\end{array}$ & 0.9570 & 0.9766 & 0.9170 & 0.9779 & 0.8459 \\
\hline \multirow{2}{*}{$\begin{array}{l}\text { Compressive } \\
\text { strength }\end{array}$} & $\begin{array}{l}\text { Only } \\
\text { extra-porosity }\end{array}$ & 0.8899 & 0.9012 & 0.7547 & 0.8573 & 0.9438 \\
\hline & $\begin{array}{l}\text { Extra-porosity }+ \\
\text { plastic }\end{array}$ & 0.9539 & 0.9739 & 0.9201 & 0.9761 & 0.8401 \\
\hline \multirow[t]{2}{*}{$\begin{array}{l}\text { Young's } \\
\text { modulus }\end{array}$} & $\begin{array}{c}\text { Only } \\
\text { extra-porosity }\end{array}$ & 0.9160 & 0.9193 & 0.6196 & 0.7794 * & 0.9184 \\
\hline & $\begin{array}{l}\text { Extra-porosity }+ \\
\text { plastic }\end{array}$ & 0.9819 & 0.9944 & 0.8373 & 0.9795 & 0.8608 \\
\hline
\end{tabular}

${ }^{*}$ limited bound on $\mathrm{p}_{\mathrm{c}}$ parameter added for allowing the fit. The fit is less reliable.

In the case where only the extra-porosity with respect to the reference sample is considered, the best model seems to be the Schiller model. On the contrary, when the plastic waste is counted as porosity, the best fit is obtained with the Ryshkewitch or the Zheng model for strength and Ryshkewitch model for Young's modulus. The Schiller model is known to be less effective for porosity values close to $0 \%$ and $100 \%$; in this case, it is clear that when the porosity range is very wide, this model is less effective, while it works much better on a narrow porosity range; also in this case, however, the divergence for zero porosity is an issue to be considered when applying this model.

An additional set of calculations was carried out considering only a fraction, $f$, of the plastic acting as pores. In this case, the effective porosity was an intermediate value between the extra-porosity with respect to the reference sample and the sum of extraporosity and plastic content. The calculation showed that the best $R^{2}$ fit is obtained again with Zheng and Ryshkewitch models, and in particular for the case in which all the plastic aggregate is considered as porosity.

Since the Zheng model approach is to consider the pores as a second phase with zero modulus, the improved accord between model and experimental data when all the plastic aggregate is considered porosity is a further confirmation of the very scarce role of plastic on the strength and stiffness of the composite.

Another observation can be made by analysing the parameters $\sigma_{0}$ and $E_{0}$ in the best fitting models, Ryshkewitch and Zheng, that represent the strength or modulus of the pore-free material (in this case the material without extra porosity). The data are shown in Table 2, as a function of the fraction, $\mathrm{f}$, of the plastic considered as porosity. When considering plastic as pores, this parameter always increases up to a value close to the experimental one. This also suggests that the plastic essentially acts as porosity. 
Table 2. Values of $\sigma_{0}$ and $E_{0}$ parameters for the Ryshkewitch and Zheng models, as a function of the fraction, $f$, of the plastic aggregate considered as porosity in the model.

\begin{tabular}{|c|c|c|c|c|c|c|}
\hline \multirow{3}{*}{$f$} & \multicolumn{4}{|c|}{$\sigma_{0}(\mathrm{MPa})$} & \multicolumn{2}{|c|}{$E_{0}(\mathrm{GPa})$} \\
\hline & \multicolumn{2}{|c|}{ Compression Strength } & \multicolumn{2}{|c|}{ Flexural Strength } & \multirow{2}{*}{ Ryshkewitch } & \multirow{2}{*}{ Zheng } \\
\hline & Ryshkewitch & Zheng & Ryshkewitch & Zheng & & \\
\hline 0 & 25.2 & 23.5 & 6.59 & 6.09 & 29.6 & $19.3 *$ \\
\hline 0.1 & 26.1 & 24.6 & 6.80 & 6.36 & 29.8 & $21.5 *$ \\
\hline 0.2 & 26.5 & 25.3 & 6.89 & 6.54 & 29.9 & $23.6^{*}$ \\
\hline 0.3 & 26.8 & 25.7 & 6.95 & 6.66 & 30.0 & 25.4 * \\
\hline 0.4 & 26.9 & 26.1 & 6.99 & 6.74 & 30.0 & $27.0 *$ \\
\hline 0.5 & 27.0 & 26.3 & 7.02 & 6.81 & 30.1 & $28.5 *$ \\
\hline 0.6 & 27.1 & 26.5 & 7.04 & 6.86 & 30.1 & $29.7 *$ \\
\hline 0.7 & 27.2 & 26.7 & 7.06 & 6.90 & 30.1 & 29.2 \\
\hline 0.8 & 27.3 & 26.8 & 7.07 & 6.93 & 30.1 & 29.2 \\
\hline 0.9 & 27.3 & 26.9 & 7.08 & 6.95 & 30.2 & 29.3 \\
\hline 1 & 27.3 & 26.9 & 7.09 & 6.97 & 30.2 & 29.3 \\
\hline
\end{tabular}

${ }^{*}$ limited bound on $\mathrm{p}_{\mathrm{c}}$ parameter added for allowing the fit. The fit is less reliable.

Thus, the models also confirm the experimental indication that a small amount of plastic waste aggregate causes a significant reduction in strength. Since plastic particles seem to behave as large-size pores, the addition of even a small amount of plastic entails a significant reduction in the strength of mortar.

These results are substantially in line with the literature on mortars/concretes containing waste materials, even if in the literature, a single typology of plastic waste, instead of a mix, was generally used $[17,18,24,25,28,38,39]$. The results are shown in Figure 4 , where the reduction in strength as a function of the plastic volume percentage inserted in mortar is shown for the selected literature and for this work.

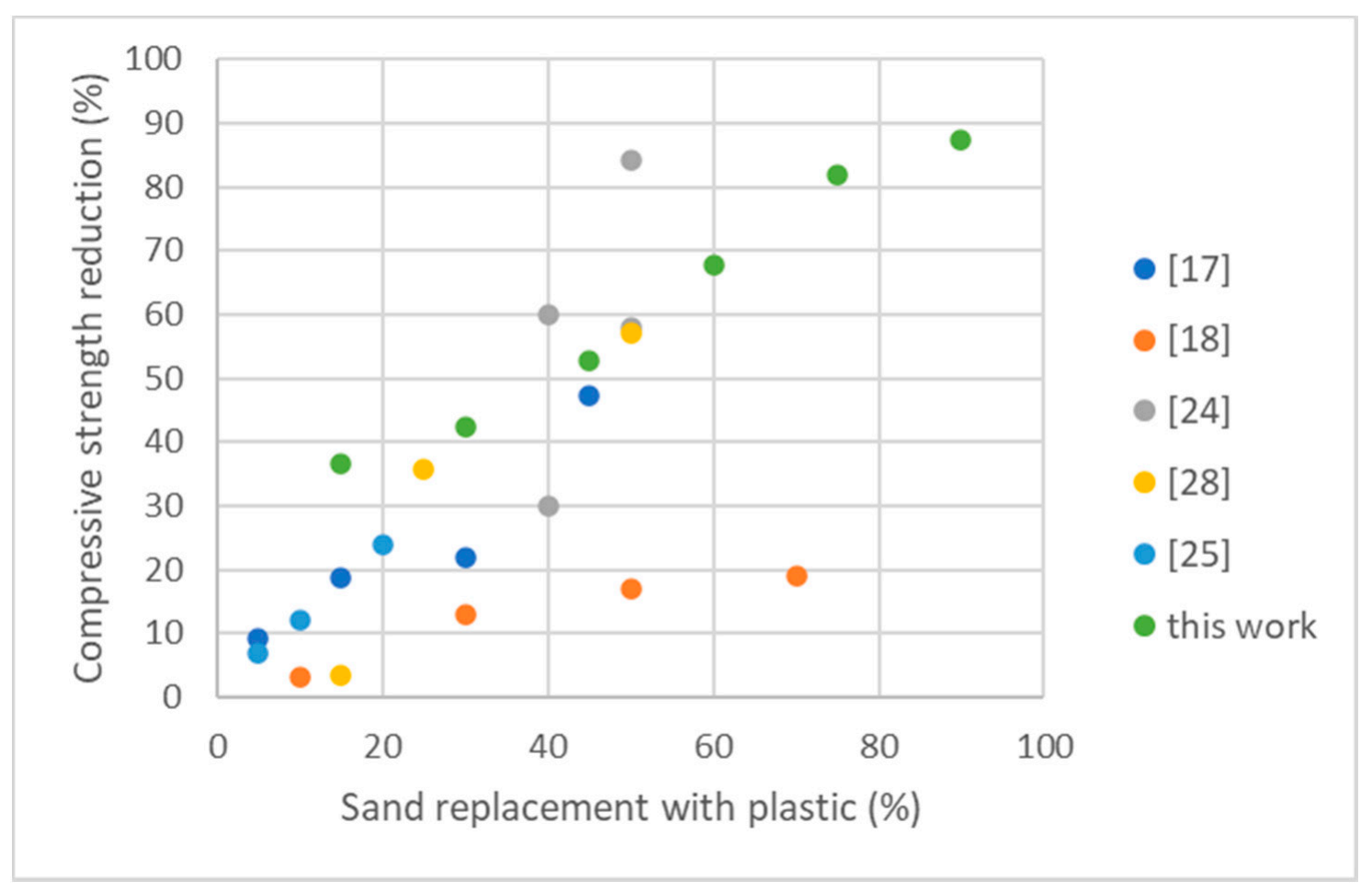

Figure 4. Comparison of compressive strength reduction with other literature work. 
The literature results generally present a lower strength reduction with a low plastic content. This effect can be ascribed, in the authors' opinion, to the fact that generally, the substituted plastic particles' size is selected to mimic the sand granulometric distribution. In this case, instead, the plastic is inserted "as is", and in fact presents a larger mean size than the sand. This fact, together with the low interface strength (if any) of the apolar plastic particles with cement, creates presence of large-size defects even at low plastic content, which cause a marked reduction in strength. At higher plastic content, instead, the data are in line with the literature, excepting the case of Senhadji et al. [18]. In this paper, they show a low strength reduction probably due to several factors: the use of rigid PVC, that is a rather polar polymer and thus has a much better interaction with cement than other polymers; the use of a very fluid mortar, both due to the high w/c ratio of 0.6 and to the presence of a superplasticizer; the very precise reconstruction of the granulometric curve of the PVC particles to mimic the sand one; and the washing and drying procedure of the PVC particles before use. All these procedures, however, entail a cost, and thus reduce the economical advantage of recycling plastic inside cement.

In this work, it was instead demonstrated that a mixed plastic waste, without prior treatment, does not behave very differently from single-plastic ones used by other researchers [18,27-29]. In fact, no matter what the type of plastic or plastic mix used, the as-received plastic waste is detrimental to mechanical properties. Since the separation of plastic waste that cannot be easily recycled is an expensive task, it is interesting that a further separation step does not significantly improve the final properties of the substituted mortar. It is also worth noting that the size of the plastic particles used in this work is higher than those currently used in the literature, suggesting that it could also be possible to limit the plastic waste grinding step without a significant further loss in mechanical properties, with a conspicuous saving in both energy and money.

\section{Materials and Methods}

\subsection{Materials}

Plastic waste derived from WEEE waste was provided by IREN S.p.A. and was characterized by the IREN laboratory. Information regarding the composition can be found in the Supplementary Materials. An American Petroleum Institute (API) oil-well Class G cement (Lafarge North America) was used in the preparation of the mortars, and details about the cement used are summarized in Table 3. The Class $\mathrm{G}$ cement required a curing time of $24 \mathrm{~h}$ at $85{ }^{\circ} \mathrm{C}$ in $100 \%$ relative humidity, which allows for the fast preparation and characterization of specimens. CEN Standard quartzite sand purchased from Societé Nouvelle Du Littoral was used as fine aggregate. This size distribution of sand lay within the specific limits of UNI EN 196-1. The granulometric distribution of waste plastic was obtained using a series of sieves and a mechanical shaker. The quantity of the retained materials per size was evaluated by a RADWAG PS 510/C/1 analytical balance.

Table 3. Composition and properties of Class G cement.

\begin{tabular}{cccc}
\hline Oxide & (wt.\%) & Phase & (wt.\%) \\
\hline $\mathrm{SiO}_{2}$ & 21.7 & $\mathrm{C} 3 \mathrm{~S}$ & 66 \\
$\mathrm{CaO}$ & 62.9 & $\mathrm{C} 2 \mathrm{~S}$ & 18 \\
$\mathrm{Al}_{2} \mathrm{O}_{3}$ & 3.2 & $\mathrm{C} 3 \mathrm{~A}$ & 7 \\
$\mathrm{Fe}_{2} \mathrm{O}_{3}$ & 2.7 & $\mathrm{C} 4 \mathrm{AF}$ & 9 \\
$\mathrm{MgO}$ & 4.3 & & \\
$\mathrm{SO}_{3}$ & 2.2 & & \\
$\mathrm{Na}_{2} \mathrm{O}$ & 0.54 & & \\
Loss on ignition & 0.74 & & \\
Insoluble residue & 0.14 & & \\
\hline
\end{tabular}


The quantities used to produce mortars are shown in Table 4 . The sand was substituted in volume percentages of $0,15,30,45,60,75$, and $90 \%$ vol for a total of seven distinct mortar mixtures. The samples are referred to in this paper as $0 \mathrm{PW}$ for no substitution with plastic and $15 \mathrm{PW}, 30 \mathrm{PW}, 45 \mathrm{PW}, 60 \mathrm{PW}, 75 \mathrm{PW}$, and $90 \mathrm{PW}$ for samples containing plastic. The number in front of the acronym corresponds to the volume percentage of natural aggregate substituted with plastic waste.

Table 4. Mix design for the mortars prepared with plastic waste.

\begin{tabular}{ccccc}
\hline Name of Sample & Cement $(\mathbf{g})$ & Water $(\mathbf{g})$ & Sand $(\mathrm{g})$ & PW $(\mathrm{g})$ \\
\hline 0 PW & 71.2 & 35.6 & 213.7 & 0 \\
$15 \mathrm{PW}$ & 71.2 & 35.6 & 181.7 & 14.8 \\
$30 \mathrm{PW}$ & 71.2 & 35.6 & 149.6 & 29.6 \\
$45 \mathrm{PW}$ & 71.2 & 35.6 & 117.6 & 44.39 \\
$60 \mathrm{PW}$ & 71.2 & 35.6 & 85.5 & 59.18 \\
$75 \mathrm{PW}$ & 71.2 & 35.6 & 53.4 & 73.97 \\
$90 \mathrm{PW}$ & 71.2 & 35.6 & 21.4 & 88.78 \\
\hline
\end{tabular}

\subsection{Preparation of Specimens}

The mortar mixing and preparation followed the guidelines of UNI EN 196-1, with a water-to-cement weight ratio (w/c) equal to 0.5 and an initial (sample $0 \mathrm{PW}$ ) sand-tocement weight ratio of 3 . The paste was poured into prismatic moulds $20 \times 20 \times 80 \mathrm{~mm}$ in size, and the samples were then cured accordingly to the requirements of the class $G$ cement.

\subsection{Density and Mechanical Properties and Optical Characterization}

Density tests, compressive tests, and 3-point flexural tests were performed in order to evaluate the influence of plastic waste as a substituent of natural aggregate in mortars. Density was evaluated by taking the measurement of width, length, and height with a caliper on polished samples; a RADWAG PS 510/C/1 analytical balance was employed to measure the sample weights. A Zwick-Line z050 single-column machine with a maximum cell load of $1 \mathrm{kN}$, a pre-load of $5 \mathrm{~N}$, and a test speed of $0.01 \mathrm{~mm} / \mathrm{min}$ was used for flexural tests. Compressive strength was measured using $20 \times 20 \times 20 \mathrm{~mm}$ cubic samples cut from the flexural test, following the ASTM C109 standard, using the same machine but with a cell load of $50 \mathrm{kN}$, a pre-load of $30 \mathrm{~N}$, and a test speed of $0.5 \mathrm{~mm} / \mathrm{min}$. At least four samples per mixture were tested, using both flexural and compressive tests. The microstructural investigation aimed at assessing the interfacial adhesion between the plastic aggregate and cement in mortar was performed using a stereomicroscope Leica EZ4 W. The samples were cut in the middle with a diamond blade in a BRILLANT 220 cutting machine and carefully mechanically polished using 400-grit silicon carbide paper (Struers).

\subsection{Characterization of Plastic Waste}

The plastic waste particles' cumulative granulometric distribution is shown in Figure 5A. The maximum size of these particles was $5 \mathrm{~mm}$, slightly higher than $4 \mathrm{~mm}$, that is generally used as the upper limit for the fine aggregate used for mortar preparation. In the figure, the difference in the granulometric distribution between the Fuller curve (blue stars) and the plastic waste (black squares) is shown. The Fuller curve represents the granulometric curve that characterizes the maximum compactness of an aggregate. The two curves do not follow similar trends, and the difference brings about non-ideal aggregate packing, possibly leading to the formation of porosity, in particular with high substitution rates. Porosity must be avoided, since it has a strong contribution to the worsening of the mechanical performance of the material [34,40]. The fineness modulus of plastic waste used was 2.5, while for standard sand, it was 3.0. 

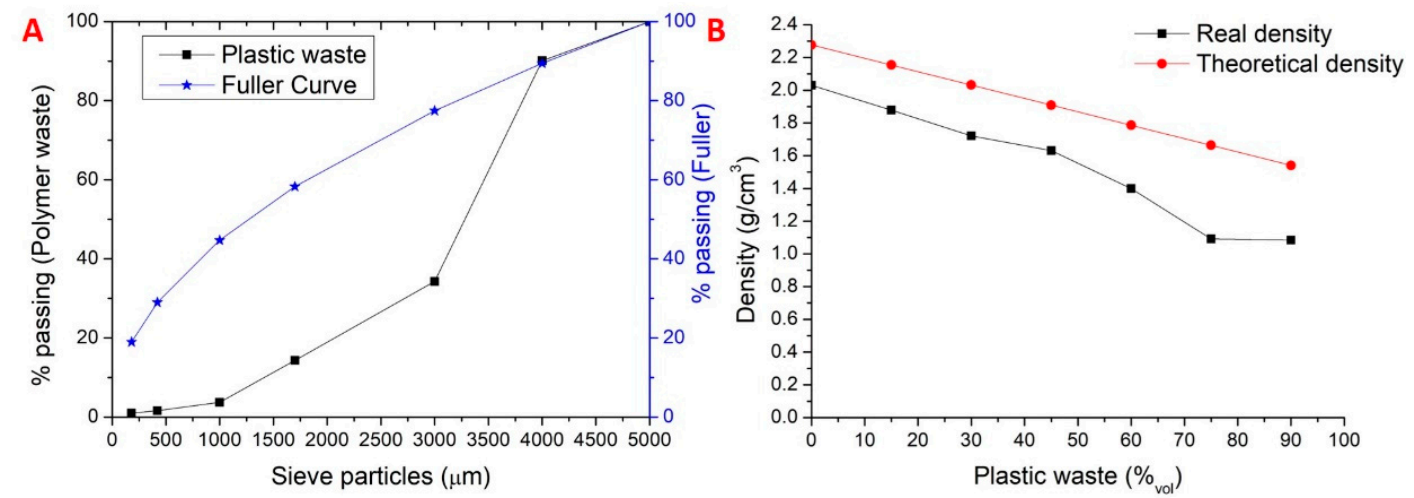

Figure 5. Fuller curve (in blue star) and cumulative granulometric distribution of plastic waste (in black square) (A) and variation of density as a function of the percentage of sand substituted with plastic waste (B).

The plastic wastes' mean particle density was estimated to be $1.2 \mathrm{~g} / \mathrm{cm}^{3}$, following similar literature assessments [41]. Since the sand density was approximately $2.6 \mathrm{~g} / \mathrm{cm}^{3}$, the density of the mortar was reduced by the substitution of sand with plastic, as presented in Figure 5B. The higher the substitution, the lower the density of the mortar. As Figure 5B shows, with high plastic waste substitutions, the real density of the samples was much lower than the theoretical value (normalized at $0 \%$ plastic waste), demonstrating that a high amount of plastic waste generates extra-porosity.

\section{Conclusions}

In conclusion, in this work, it was demonstrated that the immobilization of WEEE plastic waste in cement mortars is possible, with a well-known significant reduction in strength with compared to standard mortar.

- The use of plastic in the substitution of the aggregates reduces the density of the mortar and also decreases the need for natural resources, but still allows maintain mechanical properties sufficient for use in non-structural applications to be maintained, for instance, for use in screeds or substrates in the construction sector.

- It was demonstrated that the lower mechanical properties of plastic aggregates and in particular the lack of adhesion at the interface are the main causes of the reduction in mechanical properties of the mortars. The low adhesion of the interface generates additional porosity and reduces the mechanical contribution of the plastic itself, overall leading to a strong reduction in strength even at rather low plastic content $\left(15 \%_{\mathrm{vol}}\right)$.

- The comparison of experimental data with the main models describing the mechanical properties of porous materials confirmed the low mechanical contribution of plastic aggregates.

- To tackle the mechanical issues and to improve the properties for plastic-substitute mortars (thus allowing a more widespread use of these materials in the building sector), low-cost strategies are necessary.

Supplementary Materials: The following are available online at https:/ /www.mdpi.com/article/10 .3390 /recycling6040070/s1, Figure S1: percentage composition of the polymer mix.

Author Contributions: Conceptualization, A.M. and M.P.; data curation, L.L.; formal analysis, L.L.; investigation, A.M. and D.S.-R.; methodology, A.M. and L.L.; project administration, M.P.; resources, M.P.; supervision, L.L. and M.P.; validation, A.M., L.L. and D.S.-R.; visualization, L.L. and D.S.-R.; writing-original draft, L.L. and D.S.-R.; writing—review and editing, L.L. and M.P. All authors have read and agreed to the published version of the manuscript.

Funding: This research received no external funding.

Acknowledgments: This work was supported by IREN S.p.A. (contract No. 1029/2018). 
Conflicts of Interest: The authors declare that they have no known competing financial interests or personal relationships that could have appeared to influence the work reported in this paper.

\section{References}

1. PlasticEurope an Analysis of European Plastics Production, Demand and Waste Data. 2019. Available online: https://www. plasticseurope.org/application/files/9715/7129/9584/FINAL_web_version_Plastics_the_facts2019_14102019.pdf (accessed on 8 September 2021).

2. Anuar Sharuddin, S.D.; Abnisa, F.; Wan Daud, W.M.A.; Aroua, M.K. A Review on Pyrolysis of Plastic Wastes. Energy Convers. Manag. 2016, 115, 308-326. [CrossRef]

3. Al-Salem, S.M.; Lettieri, P.; Baeyens, J. Recycling and Recovery Routes of Plastic Solid Waste (PSW): A Review. Waste Manag. 2009, 29, 2625-2643. [CrossRef]

4. Gu, L.; Ozbakkaloglu, T. Use of Recycled Plastics in Concrete: A Critical Review. Waste Manag. 2016, 51, 19-42. [CrossRef] [PubMed]

5. Dan Gavriletea, M. Environmental Impacts of Sand Exploitation. Analysis of Sand Market. Sustainability 2017, 9, 1118. [CrossRef]

6. Ferrè, F.; Via, A.; Ausiello, G.; Brannetti, B.; Zanzoni, A.; Helmer-Citterich, M. Sustainable Development and the Exploitation of Mineral and Energy Resources: A Review. Int. J. Earth Sci. 2002, 91, 723-745. [CrossRef]

7. Puneeth, H.C.; Mahendra, S.P.; Rohith, M.; Naveenkumar, K. Replacement of Fine Aggregates by Recycled Construction and Demolition Waste in Pavement Quality Concrete; Das, B.B., Neithalath, N., Eds.; Springer: Singapore, 2019; ISBN 978-981-13-3317-0.

8. Lavagna, L.; Nisticò, R.; Sarasso, M.; Pavese, M. An Analytical Mini-Review on the Compression Strength of Rubberized Concrete as a Function of the Amount of Recycled Tires Crumb Rubber. Materials 2020, 13, 1234. [CrossRef] [PubMed]

9. Nisticò, R.; Lavagna, L.; Versaci, D.; Ivanchenko, P.; Benzi, P. Chitosan and Its Char as Fillers in Cement-Base Composites: A Case Study. Boletín De La Soc. Española De Cerámica Y Vidr. 2020, 59, 186-192. [CrossRef]

10. Ismail, Z.Z.; AL-Hashmi, E.A. Recycling of Waste Glass as a Partial Replacement for Fine Aggregate in Concrete. Waste Manag. 2009, 29, 655-659. [CrossRef] [PubMed]

11. Nisticò, R.; Lavagna, L.; Boot, E.A.; Ivanchenko, P.; Lorusso, M.; Bosia, F.; Pugno, N.M.; D’Angelo, D.; Pavese, M. Improving Rubber Concrete Strength and Toughness by Plasma-induced End-of-life Tire Rubber Surface Modification. Plasma Process. Polym. 2021, 18, 2100081. [CrossRef]

12. Suarez-Riera, D.; Merlo, A.; Lavagna, L.; Nisticò, R.; Pavese, M. Mechanical Properties of Mortar Containing Recycled Acanthocardia Tuberculata Seashells as Aggregate Partial Replacement. Boletín De La Soc. Española De Cerámica Y Vidr. 2021, 60, 206-210. [CrossRef]

13. Sharma, R.; Bansal, P.P. Use of Different Forms of Waste Plastic in Concrete-A Review. J. Clean. Prod. 2016, 112, 473-482. [CrossRef]

14. Liguori, B.; Iucolano, F.; Capasso, I.; Lavorgna, M.; Verdolotti, L. The Effect of Recycled Plastic Aggregate on Chemico-Physical and Functional Properties of Composite Mortars. Mater. Des. 2014, 57, 578-584. [CrossRef]

15. Badache, A.; Benosman, A.S.; Senhadji, Y.; Mouli, M. Thermo-Physical and Mechanical Characteristics of Sand-Based Lightweight Composite Mortars with Recycled High-Density Polyethylene (HDPE). Constr. Build. Mater. 2018, 163, 40-52. [CrossRef]

16. Benosman, A.S.; Taïbi, H.; Senhadji, Y.; Mouli, M.; Belbachir, M.; Bahlouli, M.I. Plastic Waste Particles in Mortar Composites: Sulfate Resistance and Thermal Coefficients. Prog. Rubber Plast. Recycl. Technol. 2017, 33, 171-202. [CrossRef]

17. Kou, S.C.; Lee, G.; Poon, C.S.; Lai, W.L. Properties of Lightweight Aggregate Concrete Prepared with PVC Granules Derived from Scraped PVC Pipes. Waste Manag. 2009, 29, 621-628. [CrossRef]

18. Senhadji, Y.; Siad, H.; Escadeillas, G.; Benosman, A.S.; Chihaoui, R.; Mouli, M.; Lachemi, M. Physical, Mechanical and Thermal Properties of Lightweight Composite Mortars Containing Recycled Polyvinyl Chloride. Constr. Build. Mater. 2019, 195, 198-207. [CrossRef]

19. Agarwal, L.K.; Felix, P.S. Strength and Behavior of Concrete Contains Waste Plastic (High Density PVC) Aggregates As Partial Replacement of Coarse Aggregates. Int. J. Eng. Res. Technol. 2019, 8, 1044-1049.

20. Najjar, A.M.K.; Basha, E.A.; Milad, B.K. Rigid Polyvinyl Chloride Waste for Partial Replacement of Natural Coarse Aggregate in Concrete Mixture. Int. J. Chem. Environ. Eng. 2013, 4, 399-403.

21. Bolat, H.; Erkus, P. Use of Polyvinyl Chloride (PVC) Powder and Granules as Aggregate Replacement in Concrete Mixtures. Sci. Eng. Compos. Mater. 2016, 23, 209-216. [CrossRef]

22. Gesoglu, M.; Güneyisi, E.; Hansu, O.; Etli, S.; Alhassan, M. Mechanical and Fracture Characteristics of Self-Compacting Concretes Containing Different Percentage of Plastic Waste Powder. Constr. Build. Mater. 2017, 140, 562-569. [CrossRef]

23. Merlo, A.; Lavagna, L.; Suarez-Riera, D.; Pavese, M. Mechanical Properties of Mortar Containing Waste Plastic (PVC) as Aggregate Partial Replacement. Case Stud. Constr. Mater. 2020, 13, e00467. [CrossRef]

24. Almeshal, I.; Tayeh, B.A.; Alyousef, R.; Alabduljabbar, H.; Mohamed, A.M. Eco-Friendly Concrete Containing Recycled Plastic as Partial Replacement for Sand. J. Mater. Res. Technol. 2020, 9, 4631-4643. [CrossRef]

25. Mustafa, M.A.-T.; Hanafi, I.; Mahmoud, R.; Tayeh, B.A. Effect of Partial Replacement of Sand by Plastic Waste on Impact Resistance of Concrete: Experiment and Simulation. Structures 2019, 20, 519-526. [CrossRef]

26. Senhadji, Y.; Escadeillas, G.; Benosman, A.S.; Mouli, M.; Khelafi, H.; Kaci, S.O. Effect of Incorporating PVC Waste as Aggregate on the Physical, Mechanical, and Chloride Ion Penetration Behavior of Concrete. J. Adhes. Sci. Technol. 2015, 29, 625-640. [CrossRef] 
27. Hussein, H.H.; Ahmed, M.K. Mechanical, Thermal and Acoustical Properties of Concrete with Fine Polyvinyl Chloride (PVC). Iraqi J. Civ. Eng. 2016, 12, 81-91.

28. Abed, J.M.; Khaleel, B.A.; Aldabagh, I.S.; Sor, N.H. The Effect of Recycled Plastic Waste Polyethylene Terephthalate (PET) on Characteristics of Cement Mortar. J. Phys. Conf. Ser. 2021, 1973, 012121. [CrossRef]

29. Dawood, A.O.; AL-Khazraji, H.; Falih, R.S. Physical and Mechanical Properties of Concrete Containing PET Wastes as a Partial Replacement for Fine Aggregates. Case Stud. Constr. Mater. 2021, 14, e00482. [CrossRef]

30. Saikia, N.; de Brito, J. Waste Polyethylene Terephthalate as an Aggregate in Concrete. Mater. Res. 2013, 16, 341-350. [CrossRef]

31. Balshin, M.Y. Relation of Mechanical Properties of Powder Metals and Their Porosity and the Ultimate Properties of Porous Metal-Ceramic Materials. Dokl. Akad. Nauk SSSR 1949, 67, 831-834.

32. RYSHKEWITCH, E. Compression Strength of Porous Sintered Alumina and Zirconia. J. Am. Ceram. Soc. 1953, 36, 65-68. [CrossRef]

33. HASSELMAN, D.P.H. Griffith Flaws and the Effect of Porosity on Tensile Strength of Brittle Ceramics. J. Am. Ceram. Soc. 1969, 52, 457. [CrossRef]

34. Chen, X.; Wu, S.; Zhou, J. Influence of Porosity on Compressive and Tensile Strength of Cement Mortar. Constr. Build. Mater. 2013, 40, 869-874. [CrossRef]

35. Schiller, K.K. Strength of Porous Materials. Cem. Concr. Res. 1971, 1, 419-422. [CrossRef]

36. Song, Y.; Zhou, J.; Bian, Z.; Dai, G. Pore Structure Characterization of Hardened Cement Paste by Multiple Methods. Adv. Mater. Sci. Eng. 2019, 2019, 1-18. [CrossRef]

37. Winslow, D.; Liu, D. The Pore Structure of Paste in Concrete. Cem. Concr. Res. 1990, 20, 227-235. [CrossRef]

38. Saikia, N.; de Brito, J. Use of Plastic Waste as Aggregate in Cement Mortar and Concrete Preparation: A Review. Constr. Build. Mater. 2012, 34, 385-401. [CrossRef]

39. Almeshal, I.; Tayeh, B.A.; Alyousef, R.; Alabduljabbar, H.; Mustafa Mohamed, A.; Alaskar, A. Use of Recycled Plastic as Fine Aggregate in Cementitious Composites: A Review. Constr. Build. Mater. 2020, 253, 119146. [CrossRef]

40. Odler, I.; Rossler, M. Investigations on the Relationship between Porosity, Structure and Strength of Hydrated Portland Cement Pastes 1. Effect of Porosity. Cem. Concr. Res. 1985, 15, 320-330. [CrossRef]

41. Thorneycroft, J.; Orr, J.; Savoikar, P.; Ball, R.J. Performance of Structural Concrete with Recycled Plastic Waste as a Partial Replacement for Sand. Constr. Build. Mater. 2018, 161, 63-69. [CrossRef] 